\title{
Gold Casting Alloys
}

\section{THE EFFECT OF ZINC ADDITIONS ON THEIR BEHAVIOUR}

\author{
Christoph J. Raub and Dieter Ott
}

Forschungsinstitut für Edelmetalle und Metallchemie, Schwäbisch Gmünd, Federal Republic of Germany

\begin{abstract}
Investment casting is widely used in the production of jewellery. In contrast to the state of affairs in other branches of the metal-working industry, however, specially developed alloys are not employed in casting gold jewellery. General purpose alloys, selected on the basis of caratage and colour, are mostly used. Their technological characteristics such as bardness (as a measure of ease of deformation) and their behaviour during casting are often given little consideration. The effect of additions of small amounts of zinc on the casting bebaviour of 14 and 18 carat gold alloys bas been studied and is discussed in this article.
\end{abstract}

In the course of research carried out on the influence of small additions of different elements on the melting and casting behaviour of gold alloys, it has been shown that alloys can be obtained which are better suited for casting purposes. Such additions of zinc have proved especially beneficial in this regard. Zinc in relatively high concentrations has been occasionally used in jewellery alloys, nearly always as a constituent of white gold alloys.

Discussed below are the results obtained from a study of the influence of additions of zinc on the casting behaviour of 14 and 18 carat gold-silver-copper alloys. The prerequisite that such additions should not cause a pronounced change in the colour of the alloys limits the permissible concentration of zinc to below about 2 weight per cent. Up to this concentration, zinc forms solid solutions with each of the three constituents of the alloy (1). One property of zinc which is significant in respect of its addition to gold-silver-copper alloy is the relatively high stability of its oxide. The enthalpy of formation of zinc oxide is - $225 \mathrm{~kJ} /$ mole at $900^{\circ} \mathrm{C}$. By comparison, the corresponding value for cuprous oxide is $-86 \mathrm{~kJ} / \mathrm{mole}$. Additions of about 0.5 per cent zinc have therefore been used occasionally for deoxidizing purposes in yellow golds (2).

Another is the high vapour pressure of the metal, which results in losses of zinc if the alloys are repeatedly remelted or if melting or casting are performed under partial pressure.

Casting quality is determined by various criteria. The most important ones are form-filling, surface quality, porosity and void formation, ease of reaction of alloy constituents with oxygen and the mechanical properties of the solidified alloy. The relative importances of these factors depend on the casting method used. The influence of zinc on these various properties was therefore tested using two different casting methods in common use, namely static and centrifugal casting.

\section{Alloys Investigated}

The alloys which were studied are listed in Table I together with some of their properties. The basic compositions of the 14 and 18 carat alloys correspond to those of commercialiy used yellow gold alloys. The alloys were produced by melting gold of 99.99 per cent purity, silver of the same fineness, fine copper (99.9 per cent) and a copper/30 per cent zinc master alloy prepared in an argon atmosphere from electrolytic copper and zinc. The zinc and copper contents of the prepared alloys were determined after each casting.

\section{Casting Methods}

The experiments were based upon the well known lost wax casting method. For the preparation of the moulds a gypsumcontaining material supplied by Hoben Davis Ltd., U.K. was used. The mould temperature was $600^{\circ} \mathrm{C}$ and the following processes were employed:

Static Casting - in this method the alloys were melted inductively in graphite crucibles in an argon atmosphere at a pressure of $65 \mathrm{kPa}$, then cast at $1000^{\circ} \mathrm{C}$ (14 carat) or $1050-1100^{\circ} \mathrm{C}(18$ carat $)$ into the moulds after which the argon pressure was immediately increased to $100 \mathrm{kPa}$. It was found that an effective pressure difference of about $35 \mathrm{kPa}$ was sufficient to give satisfactory mould-filling and was therefore very suitable in experiments aimed at detecting exen small changes in the form-filling behaviour caused by alloying additions.

Centrifugal Casting - a 'PLATICAST' (Linn Electronic $\mathrm{GmbH}$, Hirschbach) centrifugal casting was used for these experiments. Melting was done inductively in a carbon crucible in forming gas. The casting was carried out in air at the same temperatures as those described above.

\section{Sprue Construction}

The following casting models were used in various arrangements mounted on a common central sprue: (1) One or two wax grids (Bego $\mathrm{GmbH}$, Bremen) for determining the form-filling. The percentage of the grid area of the model which was filled by the cast indicated the filling rate 
(2) One or two step wedges (length $28 \mathrm{~mm}$, width $9 \mathrm{~mm}$, heights 2.4 and $8 \mathrm{~mm}$ ) the base surfaces of which were used for roughness measurements. This casting model could also be used to investigate the influence on the surface quality of different casting cross-sections

(3) One or two gramophone record pieces (about $10 \times 25 \mathrm{~mm}$ ) for establishing the efficiency with which finely-detailed structures could be reproduced

(4) One dumb-bell ( $16 \mathrm{~mm}$ long, $8 \mathrm{~mm}$ maximum diameter) for density measurements and for use as tensile test specimens (in accordance with DIN 13 906). This was mounted on a plate and cast by introduction of molten metal from below.

\section{Interfacial Tension and Angle}

A simplified version of the so-called sessile-drop-method was used for measuring the interfacial tension $(3,4)$. For this purpose the base of the sprue (sessile drop) which solidified in the funnel-shaped mould entrance was sectioned radially. After grinding and polishing, the melting angle, and from this the interfacial tension at the solidification temperature, could be determined. The exact calculation of the surface tension requires, however, that the melt does not wet the investment (wetting angle larger than $90^{\circ}$ ). This simple method is quite suitable for the characterization of casting alloys (5).

Since the variables of interest in this work are strongly influenced by the casting atmosphere, all experiments were carried out in argon.

\section{Melting Behaviour}

In addition to the casting quality, the behaviour of the gold alloy during melting and, especially in jewellery casting, repeated remelting of scrap material is of great importance in practical casting. It might be expected that, during melting, high zinc losses from the alloy might occur due to the high vapour pressure of this metal and its high affinity for oxygen, thus limiting the extent to which scrap material could be used in the production of jewellery. To test this assumption, alloys melted and cast in argon were remelted three times in air and then cast in the centrifugal process. After each cast, the zinc concentrations in the gold alloys were determined. The zinc concentrations in the starting materials were 0.5 and 1.2 per cent for 14 carat, and 0.6 and 1.2 per cent for 18 carat yellow gold alloys.

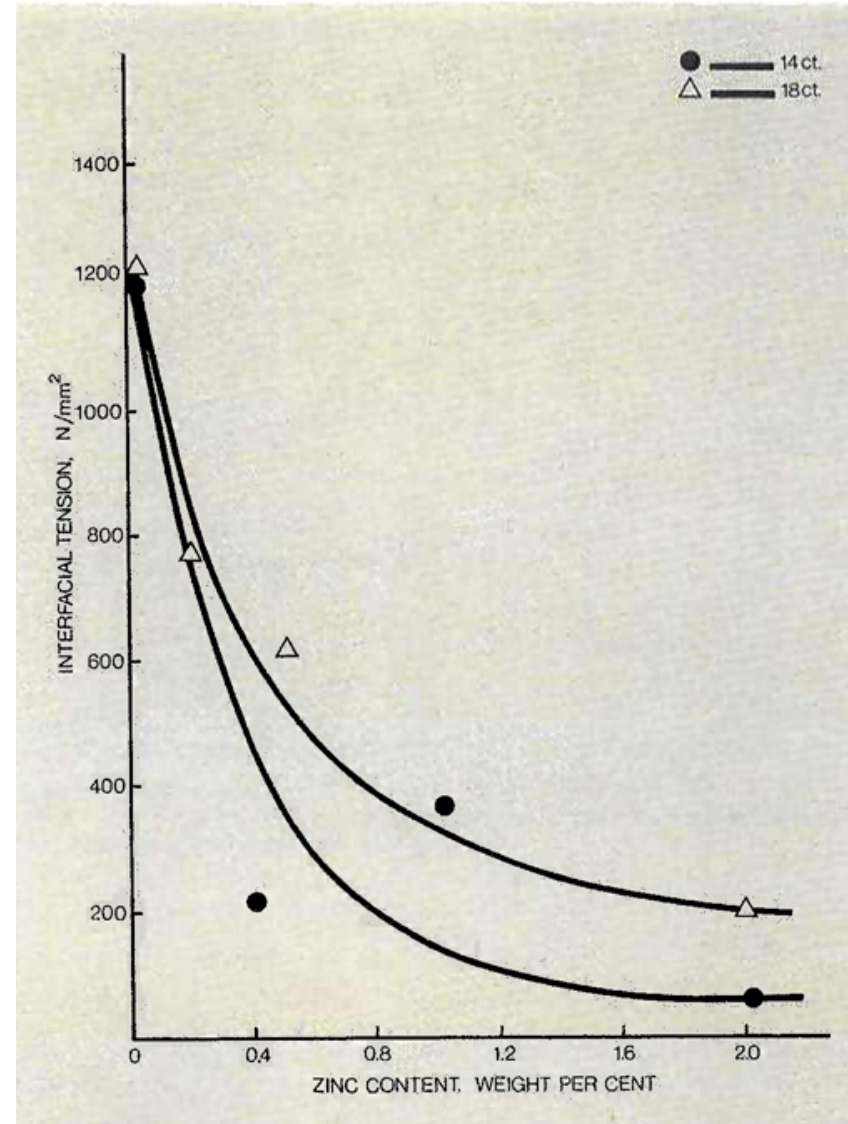

Fig. 1 The inverse relationship shown between interfacial tension and zinc content of both 14 and 18 carat yellow gold alloys
Table I

Compositions and Selected Properties of the Alloys Used

\begin{tabular}{|c|c|c|c|c|c|c|c|}
\hline \multirow[t]{2}{*}{ Alloy No. } & \multicolumn{4}{|c|}{$\begin{array}{c}\text { Composition, } \\
\text { wt. } \%\end{array}$} & \multirow{2}{*}{$\begin{array}{c}\text { Melting } \\
\text { range, } \\
{ }^{\circ} \mathrm{C}\end{array}$} & \multirow{2}{*}{$\begin{array}{c}\text { Interfacial } \\
\text { tension, } \\
\mathrm{N} / \mathrm{mm}^{2}\end{array}$} & \multirow{2}{*}{$\begin{array}{c}\text { Melting } \\
\text { angle, } \\
\text { degrees }\end{array}$} \\
\hline & $\mathrm{Au}$ & $\mathrm{Ag}$ & $\mathrm{Cu}$ & $\mathrm{Zn}$ & & & \\
\hline \multicolumn{8}{|l|}{$14 \mathrm{ct}$. } \\
\hline 1 & 58.5 & 30.0 & 11.5 & - & $860-880$ & 1210 & 168 \\
\hline 2 & 58.5 & 29.5 & 11.5 & 0.5 & $805-860$ & 210 & 130 \\
\hline 3 & 58.5 & 28.9 & 11.5 & 1.1 & $810-840$ & 360 & 83 \\
\hline 4 & 58.5 & 28.1 & 11.5 & 1.9 & $790-820$ & - & $<45$ \\
\hline \multicolumn{8}{|l|}{$18 \mathrm{ct}}$. \\
\hline 5 & 75.0 & 16.0 & 9.0 & - & $890-910$ & 1230 & 152 \\
\hline 6 & 75.0 & 15.8 & 9.0 & 0.2 & & 770 & 130 \\
\hline 7 & 75.0 & 15.5 & 9.0 & 0.5 & $870-900$ & 266 & 109 \\
\hline 8 & 75.0 & 14.9 & 9.0 & 1.1 & $850-880$ & 30 & 106 \\
\hline 9 & 75.0 & 14.1 & 9.0 & 1.9 & & - & $<45$ \\
\hline
\end{tabular}




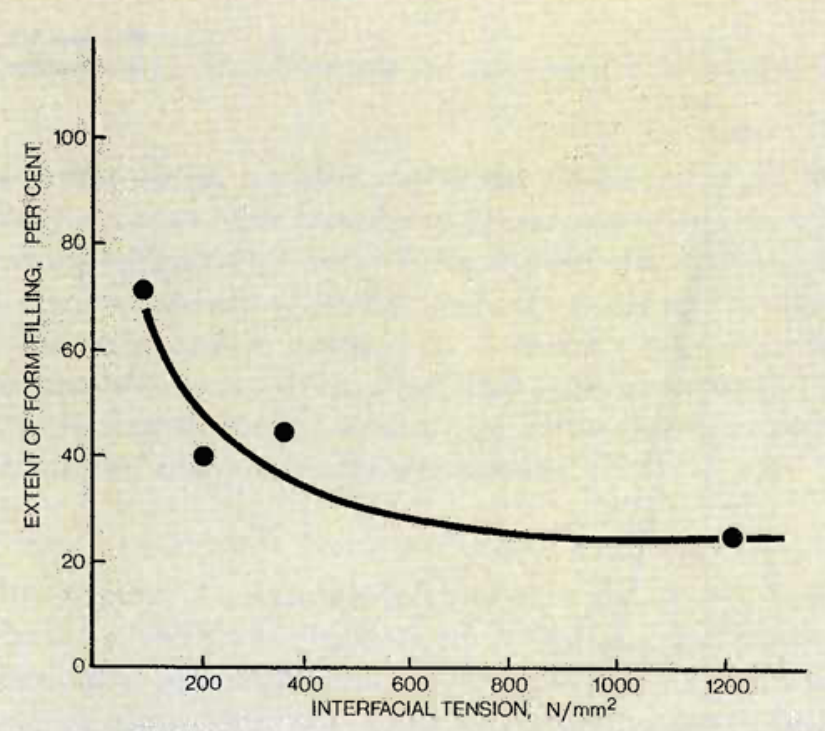

Fig. 2 The dependence of the extent of form-filling on the interfacial tension shown for a 14 carat yellow gold alloy

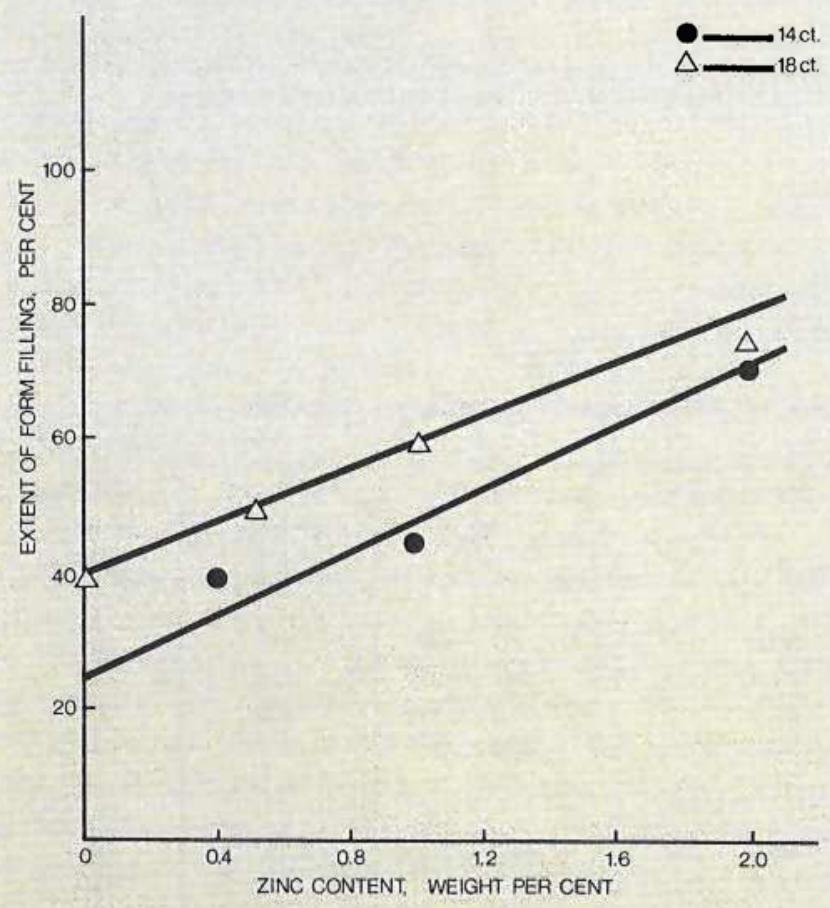

Fig. 3 The relationship between form filling and the zinc content of 14 and 18 carat yellow gold alloys (grids cast under identical conditions)

\section{Results}

\section{Casting Behaviour}

The data obtained in the experiments on interfacial tension and angle are listed in Table I and illustrated in Figure 1, At higher concentrations it can be seen that zinc strongly diminishes the wetting angle. Under the given experimental conditions, complete wetting of the investment was observed at a zinc concentration of about 2 per cent. At about 1 per cent, wetting was irregular. Wetting angles between 45 and $130^{\circ}$ were found, indicating that equilibrium was not reached during the short cooling period before solidification.

The influence of zinc on interfacial tension was found to be very pronounced in both 14 and 18 carat gold alloys (Figure 1). Interfacial tension decreased rapidly with additions of less than 0.5 per cent zinc, but the rate of decrease fell significantly with zinc additions of more than 1.5 per cent. The extent of this decrease could not be determined accurately by the method used in the present work since wetting of the investment occurred.

Among the various factors influencing form-filling, surface tension plays a very important role. Figure 2 shows how filling of Bego grids with 14 carat gold alloys depends on the interfacial tension. These results were obtained by static casting in an argon atmosphere. The dependence of form-filling on the zinc concentration for 14 and 18 carat alloys is shown in Figure 3 . The values are widely scattered and are comparable only if all other casting parameters are identical. However it can be seen that form-filling by both 14 and 18 carat alloys is greatly improved by the addition of zinc as illustrated for 14 carat alloys in the photographs shown in Figures 4 and 5 . The main reasons for this are the reduction of the interfacial tension and the lowering of the liquidus temperature.

For 18 carat yellow gold alloys liquidus and solidus temperatures are lowered by 30 and $40 \mathrm{~K}$ respectively by the addition of 1 per cent zinc. The corresponding reductions are 40 and $50 \mathrm{~K}$ for 14 carat alloys.

With the addition of zinc an improvement of surface quality is obtained as a result of reduced interfacial tension. Zinccontaining gold alloys are less prone to dendritic surface structure, which is often observed on heavy articles cast in an inert or reducing atmosphere, and the accompanying surface roughness is much reduced. Figures 6 and 7 are typical surface profile recordings, measured on step wedges which were cast in argon under the conditions discussed above. Figure 6 shows the higher surface roughness of zinc-free gold alloys and of objects with big cross-sections. Additions of 1 to 2 per cent zinc cause a pronounced reduction in roughness as can be seen in Figure 7 which illustrates the surface roughness of an 18 carat yellow gold alloy containing 2 per cent $z$ inc. The same effects were observed with 14 carat alloys. 


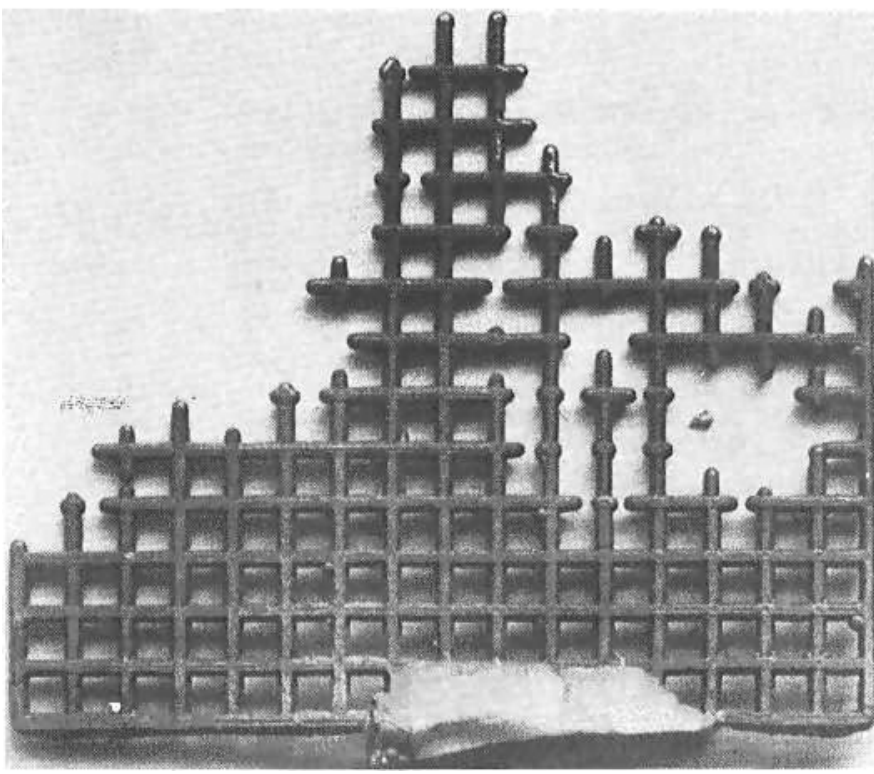

Fig. 4 The form filling of a grid by a 14 carat yellow gold without zinc showing partial filling

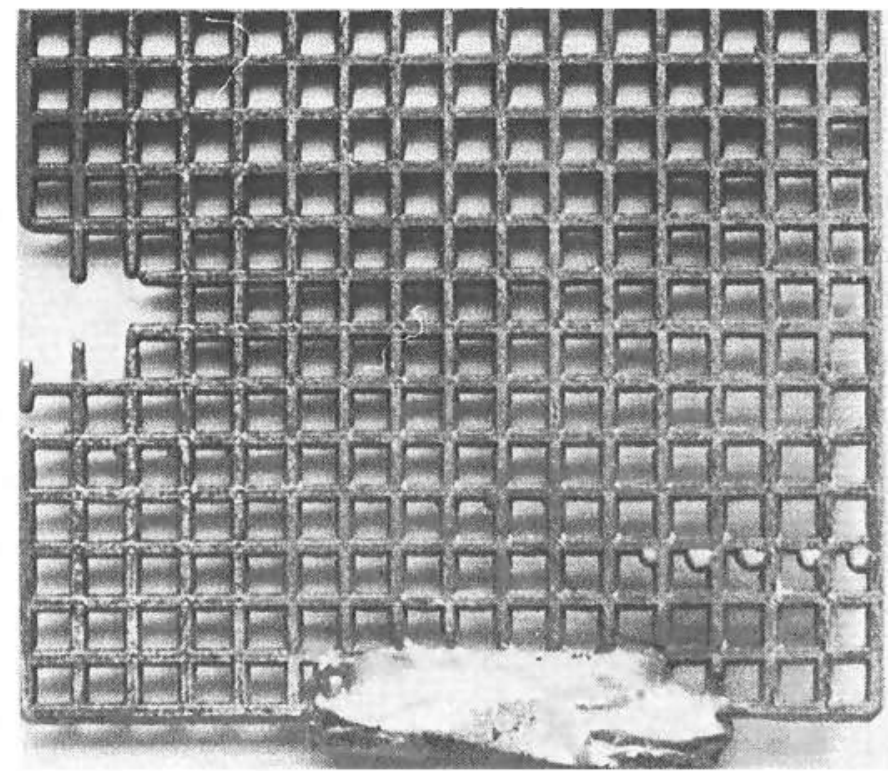

Fig. 5 The form filling of a grid by a 14 carat yellow gold containing 2 per cent zinc showing almost complete filling

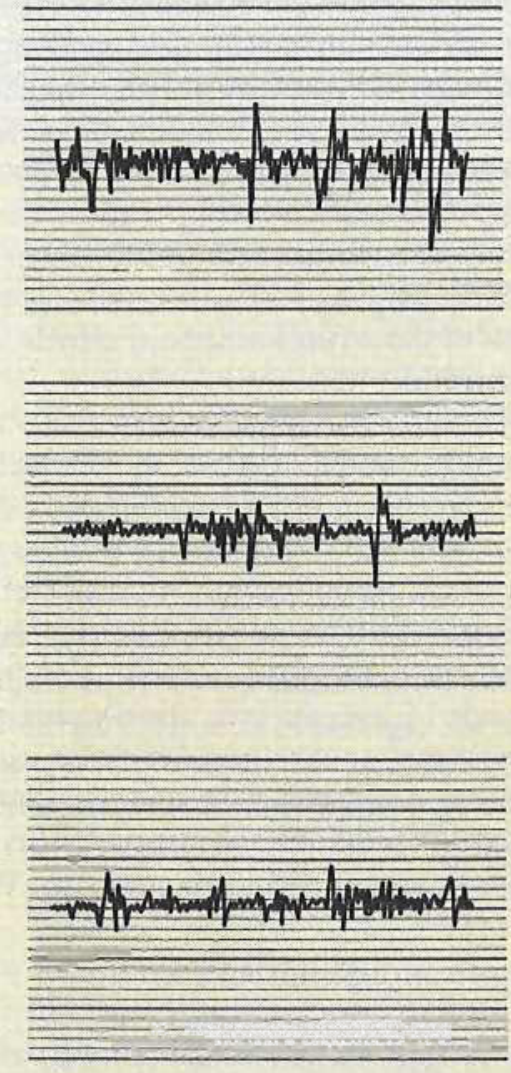

Fig. 6 (Left) Surface roughness traces, using a step wedge, of 18 carat yellow gold without zinc.

Fig. 7 (Right) Surface roughness traces, using a step wedge, of 18 carat yellow gold containing 1 per cent zinc showing marked improvement over those obtained with the zinc-free alloy
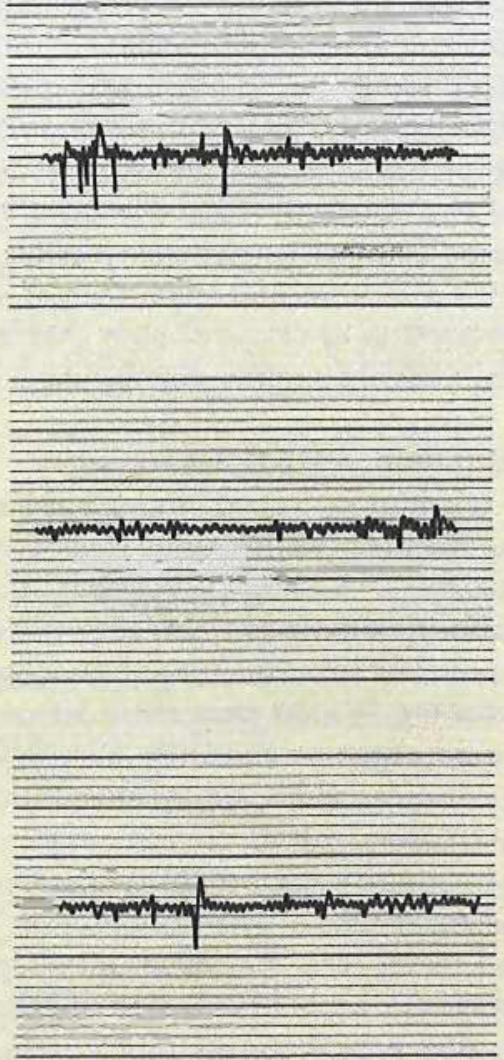


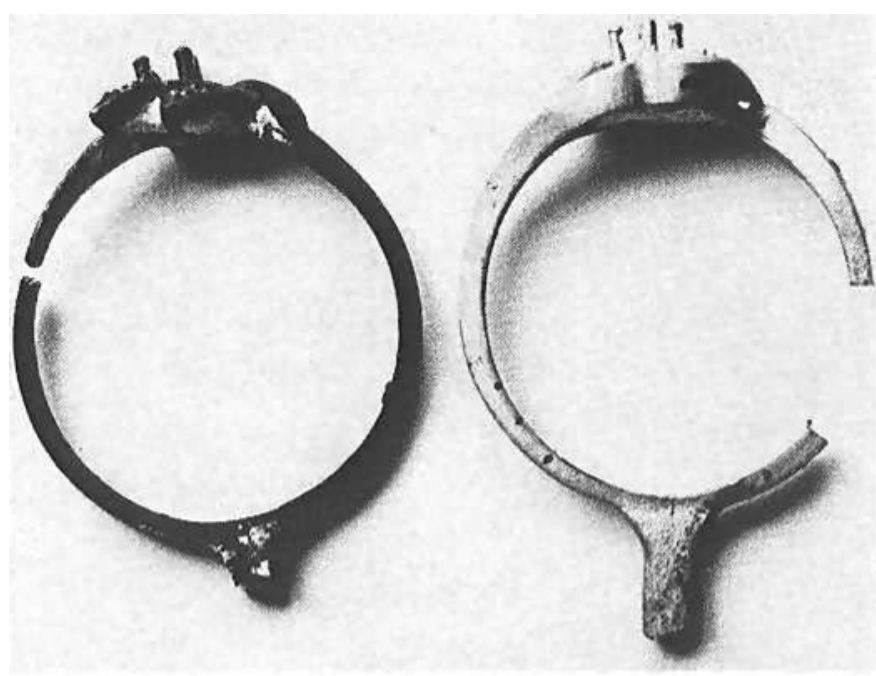

Fig. 8 The influence of zinc on the surface oxidation of 14 carat yellow gold. The ring on the left contains no zinc and has significant scale, whereas the zinccontaining ( 2 per cent) ring is almost completely free of surface oxidation

When casting in air surface defects are generally not apparent, even with zinc-free alloys, since the wetting behaviour of the melt is different due to oxidation effects. Zinc does not, therefore, have such a pronounced effect in this case. It does provide an improvement of the surface, however, which is explained by the different oxidation behaviour exhibited by zinc-free and zinc-containing gold alloys. When casting in air, copper oxide forms on the surface of the castings during cooling, but this is strongly reduced by zinc if this is present in the alloy. In the latter case, even before pickling, the surface is bright and shiny and shows only slight signs of oxidation. Figure 8 shows the surfaces of 14 carat yellow gold castings with and without additions of zinc after slow cooling in air and before pickling.

\section{Solidification Voids and Porosity}

In addition to good form-filling and low surface roughness, the absence of solidification voids is crucial for maintaining the quality of castings. Especially undesirable in jewellery production are mictovoids close to the surface, which may be exposed by subsequent production steps such as grinding and polishing. In most cases, these defects are cause for rejection or require expensive and difficult repair work. In addition to these microvoids, which are interdendritic and caused by volume contraction during solidification, gas pores can occur. Interdendritic microvoids and gas pores often form when scrap material is used or when casting in air. The detection of porosity and voids can be done metallographically, by density measurements or by tensile testing. Pores and voids in cast test samples were found to cause a large decrease in elongation, accompanied by a drop in tensile strength.
Table II

Density, Tensile Strength and Elongation of Cast Gold Alloys With and Without Zinc

\begin{tabular}{|c|c|c|c|c|}
\hline Alloy No. & $\begin{array}{l}\text { Zinc, } \\
\text { wt. } \%\end{array}$ & $\begin{array}{l}\text { Density, } \\
\mathrm{g} / \mathrm{cm}^{3}\end{array}$ & $\begin{array}{c}\text { Tensile } \\
\text { strength, } \\
\mathrm{MPa}\end{array}$ & $\begin{array}{c}\text { Elongation, } \\
\qquad \%\end{array}$ \\
\hline $14 \mathrm{ct}$. & & & & \\
\hline 1 & - & 13.2 & 217,177 & 12,3 \\
\hline 2 & 0.44 & 13.8 & 307,312 & 30,21 \\
\hline 3 & 1.10 & 13.8 & 284,320 & 19,23 \\
\hline 4 & 1.80 & 13.7 & 283,289 & 33,25 \\
\hline $18 \mathrm{ct}$. & & & & \\
\hline 5 & - & 15.0 & 281,276 & 8,15 \\
\hline 7 & 0.52 & 15.4 & 410,426 & 33,25 \\
\hline 8 & 1.10 & 15.3 & 439,416 & 25,19 \\
\hline 9 & 1.80 & 15.3 & 357,342 & 27,17 \\
\hline
\end{tabular}

Densities and measured tensile strengths for various zinc-free and zinc-containing gold alloys are listed in Table II. Scrap material was used for these alloys and the casting was done in air. Zinc-free alloys were found to be more porous and to have lower elongations and tensile strengths than their zinc-containing counterparts. By the addition of greater than 0.4 per cent zinc, the incidence of porosity was reduced and tensile properties were improved. The exact mechanism by which the additions of zinc affect the behaviour of the gold-silver-copper alloys is still unknown, and the investigations will be continued. Interaction of alloy constituents with the oxygen in the casting atmosphere and reduction by the zinc of the oxides formed apparently are not the only factors involved.

To produce void-and pore-free castings from zinc-containing gold alloys requires an uninterrupted supply of molten metal during the solidification process in order to compensate for shrinkage. If this is not achieved, for example because of improper design of the sprue, porous spongy structures with solidification microvoids are observed in the vicinity of the sprue. This does not happen to the same extent in zinc-free alloys, possibly as a result of a more even distribution of dendritic microvoids, and therefore of volume deficiency, over the whole casting. In the case of 18 carat yellow gold containing 2 per cent zinc, under certain conditions, the casting quality is diminished by an insufficient supply of melt to the solidification zone.

\section{Zinc Losses}

After remelting three times in air, the following zinc concentrations were measured: 0.52 and 1.1 per cent in 18 carat 
and 0.44 and 1.1 per cent in 14 carat. These concentrations can be compared to the starting levels of 0.6 and 1.2 per cent for 18 carat, and 0.5 and 1.2 per cent for 14 carat alloys. Thus no appreciable zinc losses had occurred. High zinc losses would be expected only at high surface to volume ratios. These may occur during melting of quite small quantities of alloys. Notwithstanding the low losses experienced in this study and in order to avoid the accumulation of impurities excessive further remelting or usage of scrap is not recommended, even with zincfree gold alloys

It was also observed that melting and casting of gold alloys with up to 2 per cent zinc can be carried out under partial gas pressure without appreciable losses of zinc by evaporation. Under $13 \mathrm{kPa}$ of argon and at the normal melting and casting temperatures, there was no noticeable zinc loss from either 14 or 18 carat yellow gold alloys, even though the melt was overheated to $1150^{\circ} \mathrm{C}$.

\section{Mechanical Properties}

Besides good casting properties, alloys used for jewellery must have acceptable mechanical properties which will allow production steps like cutting, turning and polishing to be carried out successfully. The mechanical properties of the alloys studied in this work are listed in Table III. The values obtained are scattered. The reasons for this were unavoidable differences in cooling rate. Thus the hardening due to ordering which occurs in copper-containing gold alloys was not consistent, which had a significant influence on mechanical properties. Nevertheless it is apparent that the mechanical properties of the 14 and 18 carat alloys used are not affected by zinc additions of 0.5 to 1.9 per cent.

The effect of zinc on microstructure is also small. At the highest zinc content investigated in 18 carat yellow gold (1.9 per cent), a slightly more pronounced dendritic structure was observed, which, however, did not seem to influence the alloy properties.

\section{Concluding Remarks}

The investigations have shown that addition of between 1 and 2 per cent zinc to 14 and 18 carat yellow gold-silver-copper alloys has beneficial effects on the casting behaviour of these alloys and the quality of castings. The magnitude of the effects, however, depends on the casting process in the following way:

(1) With static casting in inert gas form-filling, especially at small pressure differences, is improved. There is also a reduction of dendritic surface structure and surface quality is better

(2) With centrifugal casting in air there is a reduction in the gas porosity, which is observed under certain conditions and when scrap materials are used. There is also an improvement of surface quality due to decreased surface

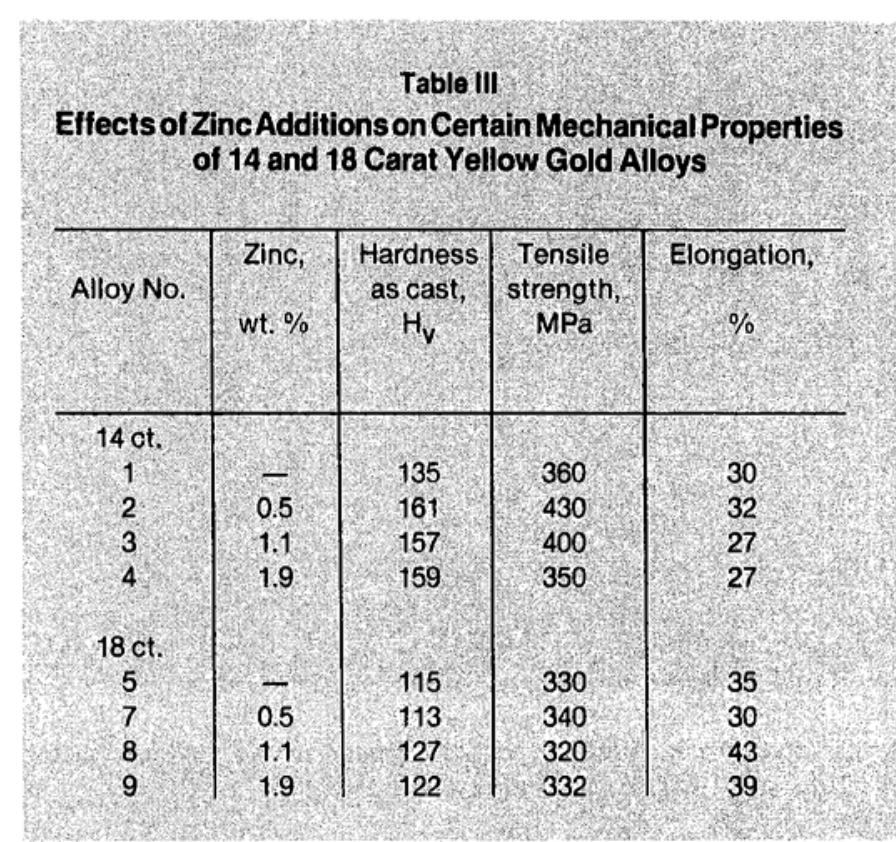

oxidation during cooling in air. In addition, form-filling is better, but this effect is less pronounced when casting in air than it is when casting is carried out in an inert atmosphere.

These beneficial influences of additions of zinc on the casting behaviour of 14 and 18 carat yellow gold alloys are considered to be due to the reduction in the surface tension and to the improvement in the oxidation behaviour of the alloys which are brought about by the additions.

\section{Acknowledgements}

The work reported above is part of a research programme supported by the International Gold Corporation Limited (Intergold), Johannesburg. The authors wish to thank Dr. G. Gafner (Intergold) for his support.

\section{References}

1 M. Hansen, 'Constitution of Binary Alloys', 2nd edition, McGraw-Hill, New York, Toronto, London, 1958, pp. 63, 242 and 650

2 W.S. Rapson and T. Groenewald, 'Gold Usage', Academic Press, London, 1978 , p. 35

3 C. Weser, G.I.T. Lab.J., 1980, 24, 642-648

4 I. Kozakevitch, in 'Physicochemical Measurements at High Temperature', Ph.D. Thesis, London University, 1959, pp. 217-222

5 D. Ott and Ch. J. Raub, unpublished work 